\title{
REAL-TIME EVALUATION OF AIR AND WATER QUALITY IN URBAN AREAS
}

\author{
MAHENDRAN $\mathbf{G}^{\mathbf{1}}$, PALANI $\mathrm{S}^{\mathbf{2}}$, SRIRAM GS ${ }^{3}$, NANDHA KUMAR $\mathrm{R}^{4} \boldsymbol{\&}$ NAVEEN G $\mathrm{K}^{\mathbf{5}}$ \\ 1,3,4,5 Department of Mechanical Engineering, R.M.K. Engineering College, Chennai, India \\ ${ }^{2}$ Department of Mechanical Engineering, VEL TECH MULTITECH, Avadi, Chennai, Tamilnadu, India
}

\begin{abstract}
Air and water are the most important elements that drive life on earth. Nowadays, the air and water resources are being polluted at a faster rate which poses a serious threat not only to humanity but also to the entire ecosystem. Results from this air and water pollution monitoring study reveal the high amount of particulate matter PM2.5, PM10 suspended in the atmospheric air due to vehicular emissions at a major road and railroad intersections in the Chennai city and Vaniyambadi Town during the month of February 2020. Construction activities are also responsible for the contribution offline and coarse particulate matter load in ambient air. The quality of air is found to get improved during the night time, especially in the residential areas. PM2.5 and PM10 levels are generally found higher in Chennai than in Vaniyambadi. The presence of tannery clusters in and around Vaniyambadi has contributed to the abnormal levels of Total Dissolved Solids TDS in the groundwater. All the data were collected autonomously in real-time using the concept of the Internet of Things IoT. Data collected were stored in a secure server for the use of future analytics. The results are aimed at identifying the hotspots of pollution which would greatly aid in the pollution prevention activities.

KEYWORDS: PM2.5, PM10, TDS, Internet of Things, Air pollution, Water pollution, Particulate Matter \& Real-time monitoring
\end{abstract}

Received: Sep 13, 2020; Accepted: Oct 04, 2020; Published: Nov 04, 2020; Paper Id.: IJMPERDOCT202021

\section{INTRODUCTION}

Over few decades, due to rapid globalization and urbanization, the quality of air and water shows tendency to become worse across the globe at an alarming rate. Air pollution is the fifth leading cause for the mortality rate in India [1]. According to the report, in 2010, over 620,000 premature deaths in India were due to the outdoor air pollution. This number had risen abruptly from 100,000 in 2000 - a six fold increase within a decade. In a very recent report, the World Health Organization (WHO) calls the air pollution as the 'silent killer' [2]. According to it, every year, around 7 million deaths are caused due to the exposure from both outdoor and household air pollution. The South-East Asian region is the most prone part to this as it had caused over 2 million deaths in this region. Though the Chennai city's air pollution levels are lower when compared with other cities like New Delhi and Kanpur [3] it is much higher than specified safe values(PM2.5 - 30 $\mu \mathrm{g} / \mathrm{m}^{3}$ and PM10 $-50 \mu \mathrm{g} / \mathrm{m}^{3}$ ) as prescribed by the Central Pollution Control Board(CPCB) [4].Now-a-days, air quality monitoring at residential sites is also becoming a necessary one.

There are barely no readily available and reliable records on pollution levels in Vaniyambadi, a major 
leather export and chemical manufacturing hub in Tamil Nadu. Groundwater is a precious source of fresh water resource that is available readily. It is being exploited and polluted by population growth and the rapid expansion of industries. According to the report [5], it is estimated that approximately one-third of the world's population use groundwater for drinking. According to [6], India is the world's largest user of groundwater. The quality of water is dependent upon the chemical composition of the host rock, as well as agricultural, industrial and domestic activities. Over several decades, tanning is the predominant business in Vaniyambadi region. The augmented growth of these industries had caused irreversible damage to the water environment in the region. These industries generate large quantities of highly saline solid wastes. Large scale industries have Common Effluent Treatment Plant (CETP), but the small scale industries do not. Due to this, the solid waste and the effluent are carelessly dumped into the land and it finds its way into the groundwater during the rainfall. The current study aims to compare the air and water quality between the two regions.

Instead of monitoring all the available parameters of quality, this project focusses only on measuring critical parameters of air and water quality. Though the water quality parameters may change gradually over months, the air quality parameters are dynamic in nature. This raises the need for real-time monitoring. Alvear et al. [7] studied the possibility of using Unmanned Aerial Vehicles (UAV) in the monitoring of air quality in areas with poor accessibility and concluded with the identification of polluted areas with a short span of time. Xiaojun et al. [8] studied and developed a system that can monitor real-time air pollution with a reduced hardware cost. Ali et al. [9] studied the possibility of using GPRS-sensors array for real-time air pollution monitoring and conducted study in and around Sharjah, UAE. Mukta et al. [10] developed a smart water quality monitoring system that uses fast forest binary classifier to classify whether the test sample is fit for drinking. Pranata et al. [11] used an IoT based water quality monitoring system and established the relationship between water temperature and $\mathrm{pH}$.

The present study carried out provides a snapshot of the pollution levels at the sampling sites and the results are expected to help identify the 'hotspots' of pollution and aid in evaluating the risk from air and water pollution.

\section{MATERIALS AND METHODS}

\subsection{Study Area}

Three sites were chosen each in Kolathur and Vaniyambadi region. The sampling sites can be found in Fig. 1. These sites are chosen based on their close proximity with traffic intersections (road and railroad), construction sites and presence of tannery. A household site which is free from heavy traffic and industry is chosen in each of the region so that to compare the results with the other sites which are more prone to pollution due to these sources. Description of the sites along with the abbreviations use henceforth can be found in Table I. 


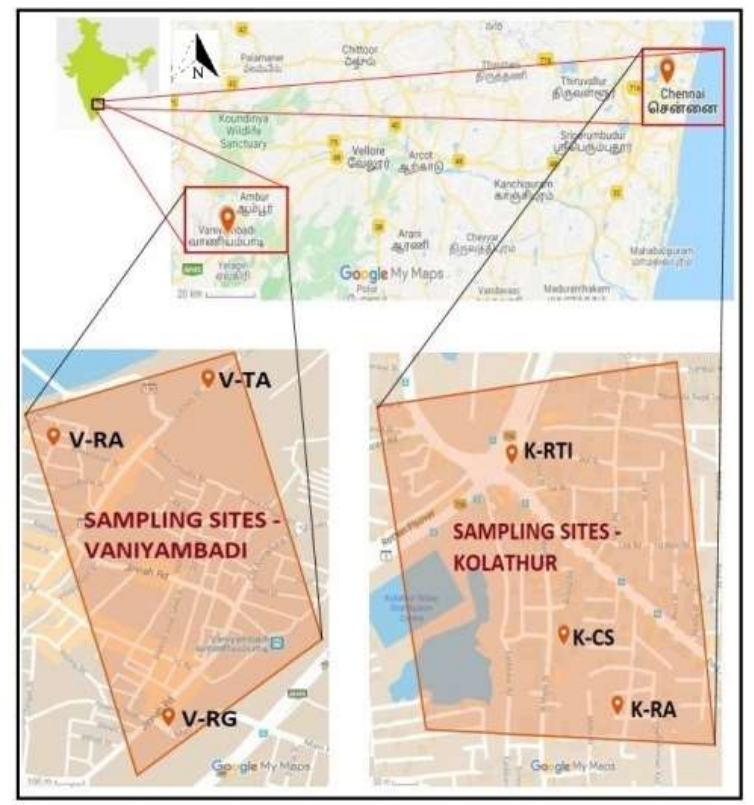

Figure 1: Map of the Sampling Sites

Table 1: Sampling Sites Description

\begin{tabular}{|c|c|l|}
\hline Sampling Site & Symbol & \multicolumn{1}{c|}{ Site Description } \\
\hline \multirow{4}{*}{ KolathurRegion $^{\mathrm{a}}$} & $\begin{array}{c}\mathrm{K}- \\
\mathrm{RTI}\end{array}$ & Near Retteri Traffic Intersection \\
\cline { 2 - 3 } & $\mathrm{K}-\mathrm{CS}$ & Near a Construction Site \\
\cline { 2 - 3 } & $\mathrm{K}-\mathrm{RA}$ & $\begin{array}{l}\text { A calm Residential Area in Girija } \\
\text { Nagar }\end{array}$ \\
\hline \multirow{5}{*}{ VaniyambadiRegion $^{\mathrm{b}}$} & $\mathrm{V}-\mathrm{TA}$ & $\begin{array}{l}\text { Near a Chemical Effluent } \\
\text { Tannery }\end{array}$ \\
\cline { 2 - 3 } & $\mathrm{V}-\mathrm{RG}$ & $\begin{array}{l}\text { Near Newtown Railway Crossing } \\
\text { Gate }\end{array}$ \\
\cline { 2 - 3 } & $\mathrm{V}-\mathrm{RA}$ & $\begin{array}{l}\text { A calm Residential Area in } \\
\text { Amburpet }\end{array}$ \\
\hline
\end{tabular}

Samples taken on $12^{\text {th }}$ February 2020

Samples taken on $20^{\text {th }}$ February 2020

The site K-RTI is chosen near the busy Kolathur Retteri junction which is a major intersection of roads connecting three major parts of Chennai viz. Perambur, Redhills and Koyambedu. Near the site K-CS, residential construction activities take place. K-RA is a household which is free from heavy traffic and industries. There are no mobility of heavy vehicles near this site. These three sites comprise the Kolathur region. The site V-RG is chosen near the busy Newtown railroad intersection. It connects the two parts of the town. This railway line is one of the busiest routes in India as it connects Chennai-Bangalore line and Chennai-Coimbatore line. Due to this, an average of 6-7 trains plies along this stretch during the peak hours which leads to accumulation of vehicles in the intersection. The site V-TA is near the tannery clusters. Similar to K-RA, V-RA household is free from traffic and industry.

\section{A. Sample Collection}

Real-time samples were collected at all the six locations for 6 hours (at each site) during the peak traffic hours (14:00 hrs to 20:00 hrs) in February 2020. The selection of the sampling sites was made after conducting the preliminary traffic volume observations conducted earlier. The air parameters which were monitored include PM2.5, PM10, air temperature and 
relative humidity. The water parameters measured include $\mathrm{pH}$ and TDS. The air temperature and relative humidity in the atmosphere were measured digitally using the DHT11 sensor. The Nova SDS011 PM sensor was used in this project to measure the particulate matters PM2.5 and PM10. It measures the articulate matter concentration using the laser scattering principle. The Robocraze $\mathrm{pH}$ meter and Gravity TDS meter were used to measure the $\mathrm{pH}$ and TDS of the water samples in the households.

These sensors are connected to the Node MCU which acts as a microcontroller unit as well as provides connectivity using the built-in Wi-Fi chip. The probes of the $\mathrm{pH}$ and TDS meters were placed in the outlet pipe of the water tanks. The outlet pipes were cleaned before the sample collection. Water from the bore wells were used to fill these tanks. The sensor data are sent to the remote cloud server. There are many cloud servers that cater the need for IoT applications. In this project, the Pub Nub cloud server is chosen for its simplicity. The Node MCU receives the data from the sensor devices and publishes the same to the Pub Nub server by using the Pub/Sub protocol. The published data was visualized in interactive charts. In addition to this, the data was also stored in the local machine using the XAMPP Apache server. These data was also visualized in real-time using the specially designed mobile applications and websites.

\section{RESULTS AND DISCUSSIONS}

\subsection{Influence of Tanneries on TDSand pH in Vaniyambadi}

The Figure 2a shows the mean of TDS and $\mathrm{pH}$ values measured at the sampling sites. It is evident from the data measured that the presence of tanneries has significant impact over the quality of the groundwater in the Vaniyambadi region. The acceptable limit of TDS in the drinking water as framed by Bureau of Indian Standards [12] should be less than 500ppm. The TDS at V-TA which is near to the tannery has the maximum value of $1750 \mathrm{ppm}$ and all the sampling sites had the TDS values more than the safety limits. The mean value of the TDS in this region is $1180 \mathrm{ppm}$. From this we can conclude that the effect of unprocessed effluents had already affected the entire region significantly. Though the TDS is less than the extreme permissible limit of $2000 \mathrm{ppm}$, steps should be taken in order to avoid the permanent damage of groundwater resource. The acceptable limit of $\mathrm{pH}$ in drinking water is in the range of 6.5-8.5. From the readings obtained, it can be concluded that the $\mathrm{pH}$ of water from the sampling sites are between the limits.

Table 2: Statistics of PM Data Measured during the Sampling Period

\begin{tabular}{|c|c|c|c|c|c|c|c|}
\hline \multirow{2}{*}{ Sampling Site } & \multicolumn{2}{|c|}{ PM2.5 Concentration $\left(\boldsymbol{\mu g} / \mathbf{m}^{\mathbf{3}}\right)$} & \multicolumn{3}{|c|}{ PM10 Concentration $\left(\boldsymbol{\mu g} / \mathbf{m}^{\mathbf{3}}\right)$} \\
\cline { 2 - 7 } & Min & Max & Mean & Min & Max & Mean \\
\hline K-RTI & 63 & 79 & 71.55 & 129 & 210 & 182.36 \\
\hline K-CS & 57 & 73 & 65.09 & 91 & 175 & 144.36 \\
\hline K-RA & 24 & 33 & 28.25 & 55 & 62 & 58.91 \\
\hline V-RG & 29 & 47 & 38.09 & 67 & 89 & 81.09 \\
\hline V-TA & 29 & 42 & 34.91 & 61 & 89 & 72.36 \\
\hline V-RA & 21 & 31 & 26.26 & 38 & 51 & 44.55 \\
\hline
\end{tabular}



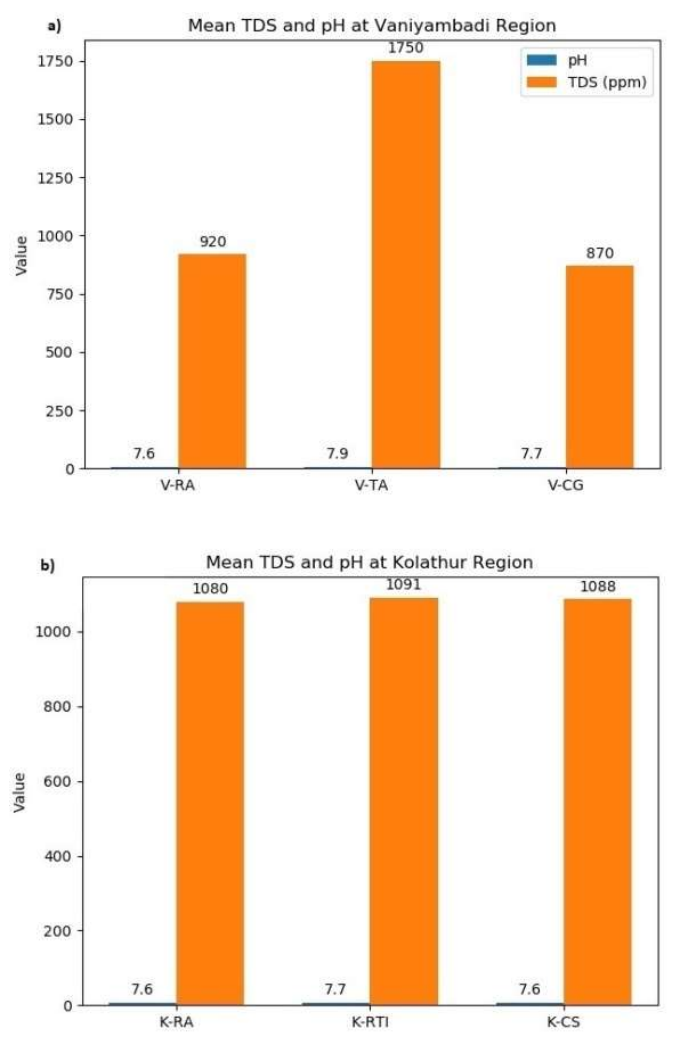

Figure 2: Variation of TDS and pH for (a) Vaniyambadi Region and (b) Kolathur Region

\section{a. Comparison of Water Quality between Two Regions}

The Figure 2 represents the mean TDS and $\mathrm{pH}$ of the sampling sites in both the regions. Based on the data measured, the $\mathrm{pH}$ of both the regions doesn't vary the most but it is not the case for TDS. The TDS of Kolathur site is high with a mean of $1086 \mathrm{ppm}$ which is very much above the permissible limit. It is lesser than the mean of Vaniyambadi region. Very high TDS levels in Kolathur can be due to its close proximity to sea. From this, we can observe that the poor water quality in Vaniyambadi is manmade and it can be increased, if rigorous and systematic efforts are taken.

\section{b. PM Concentrations at the sites}

The Fig. 3 and Fig. 4 shows the variation of the mass concentration of both the fine and coarse particles in the atmosphere at different sampling sites. Table 2 summarizes the statistical data of the particulate matter concentration at the sampling sites. The average value of PM2.5 ranges from $28.25 \mu \mathrm{g} / \mathrm{m}^{3}$ to $71.55 \mu \mathrm{g} / \mathrm{m}^{3}$ in the Kolathur region where as in Vaniyambadi it ranges from $26.26 \mu \mathrm{g} / \mathrm{m}^{3}$ to $38.09 \mu \mathrm{g} / \mathrm{m}^{3}$. The PM10 concentration ranges from $58.91 \mu \mathrm{g} / \mathrm{m}^{3}$ to 182.36 $\mu \mathrm{g} / \mathrm{m}^{3}$ in Kolathur and in Vaniyambadi it ranges from $44.55 \mu \mathrm{g} / \mathrm{m}^{3}$ to $81.09 \mu \mathrm{g} / \mathrm{m}^{3}$.

\section{c. Influence of Traffic Intersections on PM load}

The road and railroad intersections have a significant impact on the total PM load in the ambient air. The highest value of the PM2.5 and PM10 can be found in the K-RTI which is a road intersection ( $79 \mu \mathrm{g} / \mathrm{m}^{3}$ and $210 \mu \mathrm{g} / \mathrm{m}^{3}$ respectively). Similarly in Vaniyambadi, the railroad intersection V-RG has the highest value of the PM concentration $\left(47 \mu \mathrm{g} / \mathrm{m}^{3}\right.$ and $\left.89 \mu \mathrm{g} / \mathrm{m}^{3}\right)$. The higher values of the PM concentration in the Kolathur region may be due to the result of high number of vehicles that ply along this zone during the interval. All the fine and coarse PM concentrations measured in the K-RTI and V-RG sites are above the safe levels as prescribed by the CPCB. The peak level is recorded in K-RTI during the interval 
17:30 hrs to $18: 30 \mathrm{hrs}$. This can be due to the mobility of office workers, students returning back to their homes from work and classes. In the V-RG site, the maximum PM emissions were recorded during 17:00 hrs to 18:00 hrs. Since more number of trains ply during this interval, long queue of vehicles are expected at the intersection. These longer wait period of vehicles at the intersections tend to release more quantity of particulate matter in the ambient air and causes pollution.

A study conducted by Pitz et al. [13] in the underground and ground-level railroad stations in Taiwan suggested that the coarse particles are generated by the mechanical friction between the train wheels and railroad track. The study is comparable to the higher PM concentrations at the traffic intersections of the current study sites.

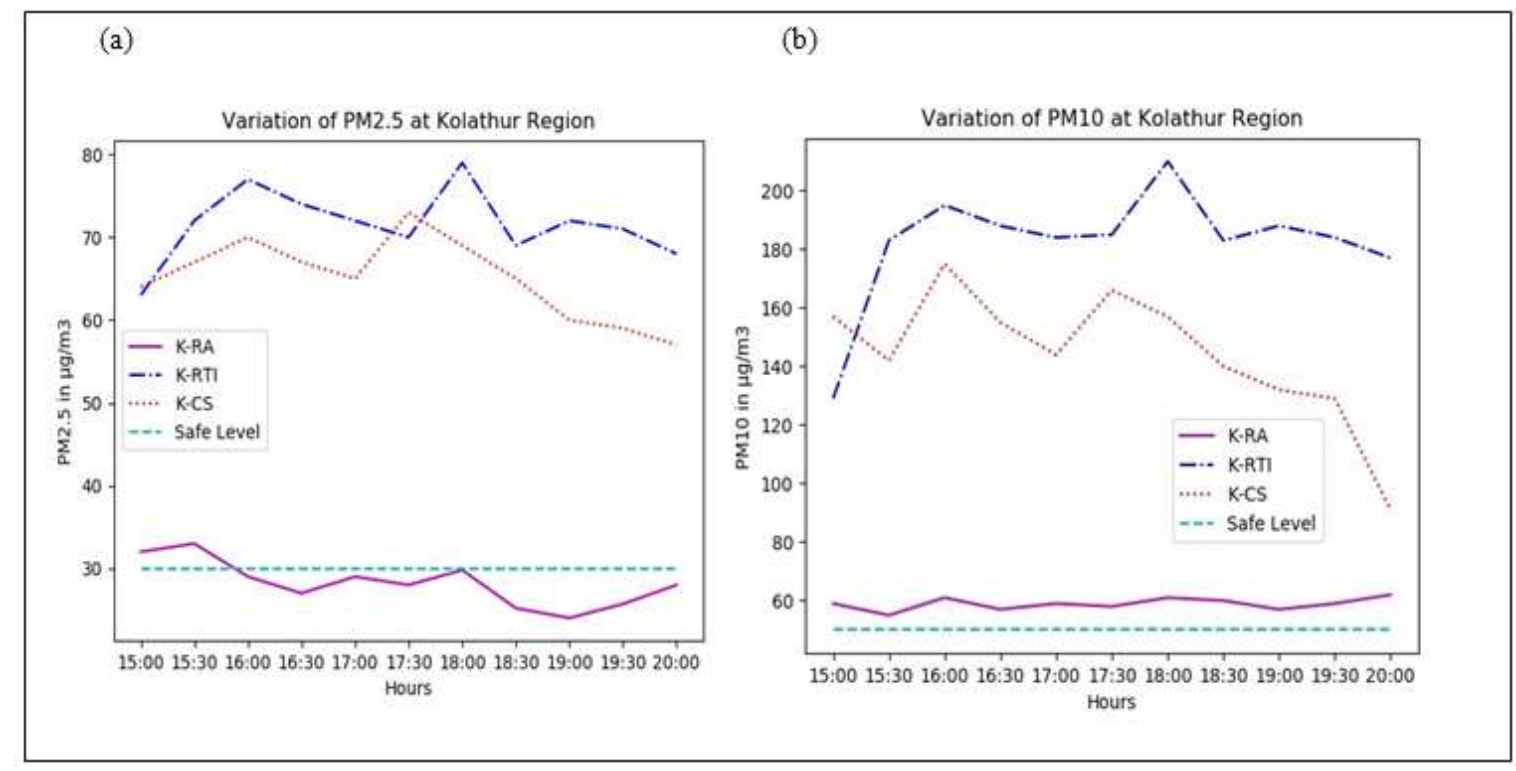

Figure 3: A Time Series of PM concentrations at Kolathur region during the Sampling Interval (a) PM2.5 (b) PM10

(a) (b)
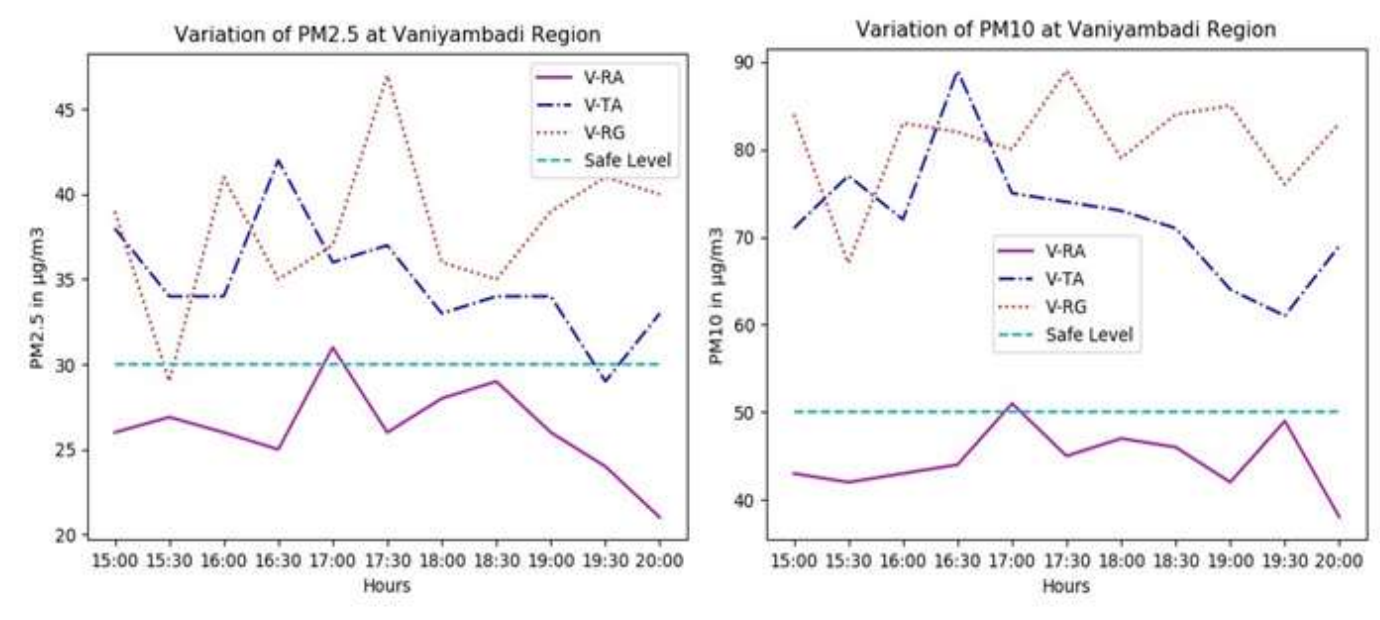

Figure 4: A time series of PM concentrations at Vaniyambadi region during the Sampling Interval (a)PM2.5 (b) PM10 


\section{d. Effect of Construction on PM load}

The other main cause for the PM emission is the construction activities. The construction sites cause coarser emissions into the ambient air. The readings from the site K-CS provides an overview of the elevated PM concentrations due to the construction activities made. The PM2.5/PM10 ratios in the Table 3 confirm the presence of PM10 concentration in more quantity. The construction activities include transportation of materials from place to place, unloading of cement bags etc. The movement of cement bags, bricks create enormous dust in the site which in turn dumps more PM load into the ambient. The PM load in these sites is starting the lower in the evening from 18:00 hrs.

Previous study made by Kumar et al. [14] concluded that the construction activities in Kanpur result in the emission of more coarse particulate matter. Observations from this study are similar and comparable with the previous study. This had confirmed that the construction sites act as one of the main reasons for the significant emissions of the coarse PM to the nearby locations in Chennai.

\section{e. Impact of Tanneries on PM Load}

Tanneries are found in clusters in Vaniyambadi region. The site V-TA primarily focuses on the leather tanning process. The leather tanning is done by processing the leather with chemical effluents. As the process doesn't involve in any combustion activities, its effect on the ambient air is lesser than that of vehicular and construction emissions. The emission from this site primarily contain coarse particulate matter. The average value of PM2.5 is $34.91 \mu \mathrm{g} / \mathrm{m}^{3}$ which is slightly higher than the safe limit.The PM10 concentration is higher in the site with a mean of $72.36 \mu \mathrm{g} / \mathrm{m}^{3}$. Though there is no combustion process that take place in the site, the mix of hazardous and non-hazardous chemical compounds in the tanning process is considered to give up certain loads of particulate matter concentrations into the ambient. This may be the cause for higher levels of PM levels and mass ratio in the sampling site.

\section{f. PM2.5/PM10 Mass Ratio}

The PM2.5/PM10 mass ratio is a non-dimensional number that is used widely in the identification of relative contributions of stationary and the mobile PM sources. A lower ration suggests that the coarse particles from the resuspension of dust and abrasion due to traffic are dominant. A higher ratio suggests that the vehicular emissions and secondary particulates are dominant. The Table 3 provides the PM mass ratio of different sites.

When compared with the six sites, the site K-RTI has higher ratio than the other sites. This can be due to the effect of more number of vehicles waiting for signal at the intersection. Earlier study conducted by Srimuruganandam and Shiva Nagendra in Chennai city [15] established the relationship of PM mass concentration in different seasons. The present mass ratios are comparable with the study and have found that the mass ratios have increased a little bit. Though the PM mass concentrations are within the safe limits in V-RA, the higher PM mass ratio may be associated with less traffic mobility in and around the corresponding site which results in less emission of coarse particles.

\section{g. Impact of Temperature anf Humidity on PM load}

The temperature and humidity are one of the fundamental parameters in the meteorological science. These data can be used to study the spread of pollution. The temperature and the humidity at the sampling sites is represented in the Fig. 5 . 


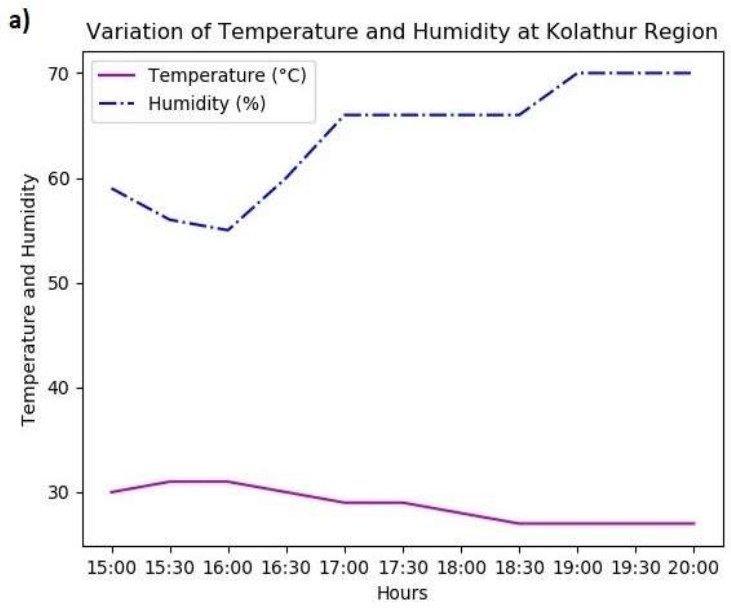

b)

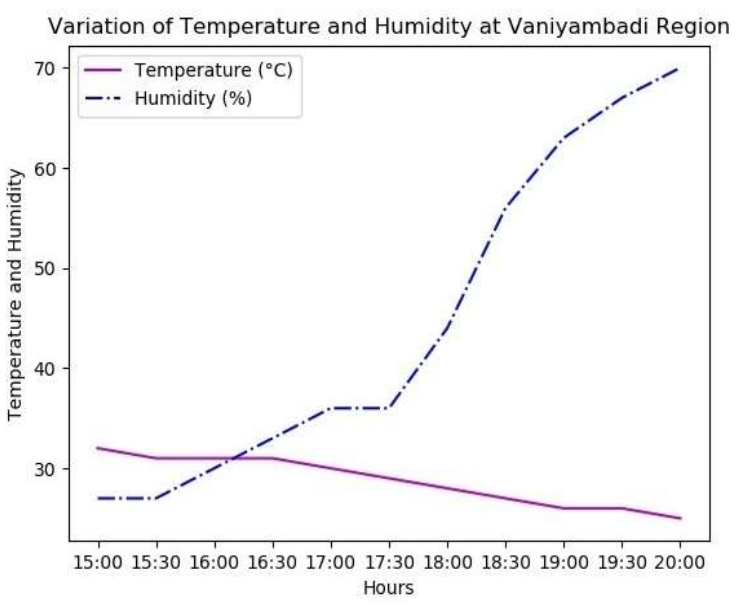

Figure 3: Variation of Temperature and Humidity in (a) Kolathur region (b) Vaniyambadi Region

Kolathur being geographically placed near the sea has higher percentage of relative humidity with a maximum of $70 \%$. whereas Vaniyambadi being an inland doesn't have a high relative humidity, but it increases during the night. In both the regions, the temperature is found to decrease in the night as expected. Though the number of vehicles in the road start to decrease after the peak hour period and the construction activities were halted at 17:30 hrs, the PM load was not reduced immediately. From Figs. 3 and 4, it is witnessed that the PM load from the site K-CS doesn't reduced a large extent till 20:00 hrs. The reduction in the PM load was found to be gradual. This gradual pattern in the PM load reduction can be illustrated from the works done by Srimuruganandam et al. [15]. In their work, they concluded that the PM emissions were found to be higher during the winter and monsoon seasons and the PM load was found to be the least during the summer. From this we may make a connection that the PM emissions are less spread when the temperature is high with a lower relative humidity and vice versa.

\section{h. PM Emissions at Residential Sites}

The PM emissions (PM2.5 and PM10) at the residential site V-RA is very well below the safe level as prescribed by the CPCB. In the site K-RA, the PM2.5 is below the safe limit, but the PM10 is slightly above the safe limit with a mean of $58.91 \mu \mathrm{g} / \mathrm{m}^{3}$. Even though, currently, the residential sites are safe from the prone of air pollution, actions should be taken to bring back the PM10 concentrations in K-RA below the safer limit of $50 \mu \mathrm{g} / \mathrm{m}^{3}$. 


\section{CONCLUSIONS}

The current study which was conducted for a short span of time confirms the poor quality of air and water in the regions studied. The PM2.5 and PM10 emissions in Chennai city have found to be increased significantly from the previously conducted studies. The role of chemical effluent tanneries in ruining the water quality of the surroundings is highlighted in the study. The role of road and railroad intersections on the PM load emissions in ambient air is established. The significance of atmospheric temperature and relative humidity in holding the PM emissions is highlighted in the study. It is fortunate to witness that the PM emissions at the residential sites of the study regions are well controlled and maintained almost below the safe levels. Steps must be taken in order to ensure its prevalence. The most important part of the study is that it provides the sources of pollution which are responsible in deteriorating the air and water quality in the regions studied. In addition to this issues, Muza ffargarh District, Pakistan. Appl Geochem 20:55-68 the current study also helped to identify the 'hotspots' of pollution in the regions. From this we can conclude that, the current pollution prevention efforts are not sufficient. Awareness must be provided to the public regarding the effects of pollution. In summary, government must revisit its pollution prevention acts and it must frame more stringent and result oriented strategies in order to establish a sustainable and safe environment

\section{ACKNOWLEDGMENT}

The authors wish to thank Prof K. Chandrasekaran, Dean of R.M.K. Engineering College. Without his help this work would have been impossible.

\section{REFERENCES}

1. GBD: Global Burden of Disease (GBD) report, World Health Organisation (WHO), 2010. https://www.cseindia.org/airpollution-is-now-the-fifth-largest-killer-in-india-says-newly-released-findings-of-global-burden-of-disease-report--4831

2. World Health Organization (WHO), 2019. https://www.who.int/airpollution/infographics/Air-pollution-INFOGRAPHICSEnglish-1.1200px.jpg?ua=1

3. India Times: WHO air pollution report: https://economictimes.indiatimes.com/news/politics-and-nation/who-air-pollutionreport-how-south-indian-cities-sit-pretty-/articleshow/64017312.cms

4. Press Information Bureau, Government of India. https://pib.gov.in/newsite/PrintRelease.aspx?relid=110654

5. Nickson RT, McArthur JM, Shrestha B, Kyaw-Nyint TO, Lowry D (2005) Arsenic and other drinking water quality issues, Muzaffargarh District, Pakistan. Appl Geochem 20:55-68

6. Namrata Chindarkar, R. Quentin Grafton, "India's depleting groundwater: When science meets policy", 2019 Wiley online library, DOI: 10.1002/app5.269

7. https://onlinelibrary.wiley.com/doi/pdf/10.1002/app5.269

8. Alvear, O., Zema, N. R., Natalizio, E., \& Calafate, C. T. (2017). Using UAV-Based Systems to Monitor Air Pollution in Areas with Poor Accessibility. Journal of Advanced Transportation, 2017, 1-14. doi:10.1155/2017/8204353

9. Xiaojun, C., Xianpeng, L., \& Peng, X. (2015). IOT-based air pollution monitoring and forecasting system. 2015 International Conference on Computer and Computational Sciences (ICCCS). doi:10.1109/iccacs.2015.736136

10. Al-Ali, A. R., Zualkernan, I., \& Aloul, F. (2010). A Mobile GPRS-Sensors Array for Air Pollution Monitoring. IEEE Sensors Journal, 10(10), 1666-1671. doi:10.1109/jsen.2010.2045890 
11. Mukta, M., Islam, S., Barman, S. D., Reza, A. W., \& Hossain Khan, M. S. (2019). Iot based Smart Water Quality Monitoring System. 2019 IEEE 4th International Conference on Computer and Communication Systems (ICCCS). doi:10.1109/ccoms.2019.8821742

12. Pranata, A. A., Jae Min Lee, \& Dong Seong Kim. (2017). Towards an IoT-based water quality monitoring system with brokerless pub/sub architecture. 2017 IEEE International Symposium on Local and Metropolitan Area Networks (LANMAN). doi:10.1109/lanman.2017.7972166

13. Bureau of Indian Standards (2012). http://cgwb.gov.in/Documents/WQ-standards.pdf

14. M. Pitz, J. Cyrys, E. Karg, A. Wiedensohler, H.E. Wichmann, and J. Heinrich. Variability of Apparent Particle Density of an Urban Aerosol. Environmental Science \& Technology. vol. 37, iss. 19, pp. 4336-4342, 2003.

15. Kumar, A., Srivastava, D., Agarwal, M., Goel, A. (2014). Sanpshot of PM Loads Evaluated at Major Road and Railway Intersections in an Urban Locality, 2014, Vol. 4 Iss. 1, PP. 23-29

16. Srimuruganandam, B., \& Shiva Nagendra, S. M. (2011). Characteristics of particulate matter and heterogeneous traffic in the urban area of India. Atmospheric Environment, 45(18), 3091-3102. doi:10.1016/j.atmosenv.2011.03.014 